\title{
Ultra Fast Electric Vehicle Battery Charger using Solar Panel/Mains Supply
}

\author{
Vaibhav Kalaskar ${ }^{1}$, Rahul Kadam ${ }^{2}$, Eaknath Idage ${ }^{3}$, Prof. V.B. Raskar ${ }^{4}$ \\ Bachelor of Engineering, E\&TC, JSPM's ICOER, Pune, India ${ }^{1,2,3}$ \\ Professor, E\&TC, JSPM's ICOER, Pune, India ${ }^{4}$
}

\begin{abstract}
In this system we are charging the battery by using our design. Since battery packs take DC power, the supply power needs to be processed by the battery charger. The manner in which power is delivered to the batteries is crucial to battery life; hence a charger also includes a control circuit for battery power management. From main supply we used step down transformer to get desired output voltage for our battery charger. We needed rectifier to convert AC to DC .Since we needed pure form of DC we design filter and obtained pure form of DC voltage .To get regulated voltage we uses regulator IC with a current controller .This system use to recharge our rechargeable battery. Similarly from solar panel we have used the solar tracker, polarity corrector and stabilizing capacitor. Concatenate it with regulator and supply coming from regulator given to the current controller to adjust the current according to increase speed to charge the battery after that auto cutoff is used for switching of the circuit from ON state to OFF state depending on battery status And this current supply is given to rechargeable battery and the charging status battery is displayed on LCD display.
\end{abstract}

Keywords: PIC16F877A Microcontroller, Relay, Solar panel, Rechargeable battery, LM317 voltage regulator.

\section{INTRODUCTION}

The vehicle (EV) battery chargers associated with an optional circulation circuit regularly raise voltage direction concerns both in the essential conveyance lines and auxiliary wires. To assess the worries and to give a superior comprehension of effects of vehicle battery stacks on the circulation voltages, a delegate reproduction model of vehicle chargers must be created. Exchanging models or definite gadget level models of vehicle chargers are precise in impersonating an extensive variety of charging conditions.

With the expanding fame of electric vehicles, there is a dire request to abbreviate the charging time, so the improvement of high-power accusing stations of quick chargers is important to ease go uneasiness for drivers. The charging station in light of the unbiased point-cinched (NPC) converter can bring many benefits, however it has unequal power issues in the bipolar dc transport.

To comprehend this issue, far reaching dc control adjusts administration (PBM) in conjunction with high-control threelevel dc-dc converter based quick charger is proposed in this paper. The dynamic dc control adjust administration (APBM) is proposed to help the focal NPC converter in adjusting power so that the extra adjusting circuit is dispensed with; while the aloof dc control adjust administration (PPBM) is proposed to dispose of the fluctuating impartial direct streams and toward guarantee the adjusted operation of quick chargers.

\section{OBJECTIVES}

To reduce the charging time this required to charge the battery. Also improve the performance of the battery. It will charge the battery within less time.

\section{III.PROBLEM IDENTIFICATION}

Presently a day, AS attainable differentiating choices to conventional inside consuming engine vehicles (ICEVs), the module cross breed electric vehicles and electric vehicles (EVs) are extending their bit of the general business a little bit at a time accordingly of decreased non-sustainable power sources use what's more, lessened ozone draining substance outpouring. Surveys show that the range per charge, the charging time, the open charging workplaces are the best stresses of clients, which are moreover the crucial components affecting their purchase of EVs. In order to allow the future in all cases usage of EVs, there is a sincere demand to develop speedy chargers to contract the charging time, besides, to pass on the high-control charging stations establishment to ease go apprehension for drivers. 


\section{RELATED WORK}

With the expanding fame of electric vehicles, there is a dire request to abbreviate the charging time, so the improvement of high-power accusing stations of quick chargers is important to ease go uneasiness for drivers. The charging station in light of the unbiased point-cinched (NPC) converter can bring many benefits, however it has unequal power issues in the bipolar dc transport. To comprehend this issue, far reaching dc control adjusts administration (PBM) in conjunction with high-control three-level dc-dc converter based quick charger is proposed in this paper. The dynamic dc control adjust administration (APBM) is proposed to help the focal NPC converter in adjusting power so that the extra adjusting circuit is dispensed with; while the aloof dc control adjust

Administration (PPBM) is proposed to dispose of the fluctuating impartial direct streams and toward guarantee the adjusted operation of quick chargers

\section{V.BLOCK DIAGRAM}

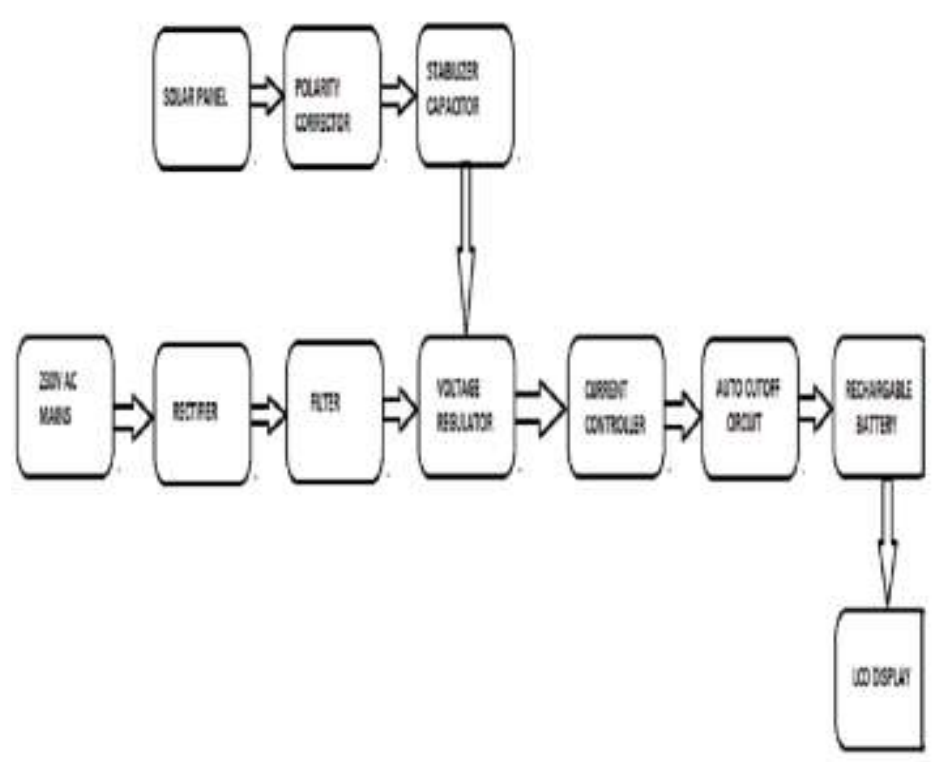

FIG.1.BLOCK DIAGRAM FOR ULTRA FAST CHARGING VEHICLE

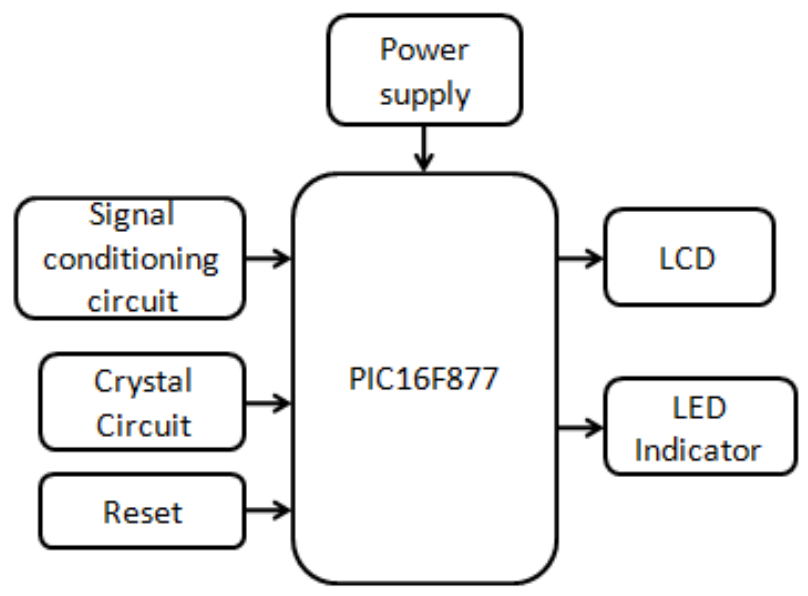

FIG.2 FOR DISPLAY THE STATUS OF BATTERY

\section{VI.WORKING}

In this system we are charging battery by using mains supply and solar panel. It consist of different parts, the first part is transformer part. Here the $230 \mathrm{~V}, 50 \mathrm{~Hz}$ AC supply is given to the transformer which is of $15 \mathrm{~V}$ step down transformer. The output of transformer is given to the rectifier circuit which is a bridge rectifier which converts AC-DC. For that rectifier it consist of 4 diodes, any two diodes conducts at a time and other two diodes does not. 
Rectifier gives the pulsating DC as a output. After the rectifier circuit there is a filter capacitor which is used to block the pulsating DC components to give only the pure DC output. There is also the LM317 voltage regulator which has 3 terminals as IN, OUT and ADJ.It is a 3 pin IC.

It gives the output between 2-30V and 5A current. At the output of regulator there is resistive load and a LED in series with that load. The LED is of 3V. The LED is used to denote the ON and OFF conditions of power supply.

And the load is used to pass the specific amount of current at the output. At the output of power supply we get $8 \mathrm{~V} / 1 \mathrm{~A}$. Also as an alternative we have used the solar panel as supply for the battery charger. here the solar panel converts the solar energy into the electrical energy which is given to polarity corrector circuitry which consists of four diodes connected in bridge .The output of polarity corrector is stabilized by using stabilizing capacitor of 1000uf .Now this voltage is also given to voltage regulator LM317. At this point where the two supplies gets switched according to condition.

The voltage regulator gives the output between $2-30 \mathrm{~V}$ and $5 \mathrm{~A}$ current. At the output of regulator there is resistive load and a LED in series with that load. The LED is of 3V. The LED is used to denote the ON and OFF conditions of system. And the load is used to pass the specific amount of current at the output. At the output of this system we get $8 \mathrm{~V} / 1 \mathrm{~A}$.

For the further process the supply form the LM317 given to the current controller and vary it according to our requirement .The current controller is the circuitry which is total used for fast charging and this current controller consists of transistor BC547 and trimmer capacitor used for vary current.

Then the output of current controller is given to the autocutoff circuit, which basically used for switching of the circuit from ON state to OFF state depending on battery status .it consists of relay which is connected in parallel with the diode switching to ON to OFF state. Output of relay goes to transistor BC547 which works on the output of comparator IC LM358 .The trimmer capacitor is connected to on terminal which used to set max. charging reference voltage , the second terminal of comparator is connected with $12 \mathrm{~V}$ battery through voltage divider circuit the comparator compares the voltage coming from these two terminals if the battery voltage is less than the reference voltage then the circuit remains $\mathrm{ON}$ and battery keeps on charging .But if battery voltage exceeds the reference voltage then the comparator provides the negative voltage to transistor and it becomes OFF and battery gets cut off from the supply as it is fully charged .

The status of the battery is displayed on the 16X2 LCD displays, which show the charging voltage of the battery accordingly by using the microcontroller PIC16F877A. For the application purpose we have used the DC motor at the output stage of battery.

\section{A.PIC 16F877A:}

PIC 16F877 is a champion among the most created microcontroller from Microchip. This controller is for the most part used for trial and propelled applications because of its minimal effort, broad assortment of usages, high bore, and straightforwardness of openness. It is perfect for applications, for example, machine control applications, estimation gadgets, think about reason.PIC16f877a discovers its applications in countless. It is utilized as a part of remote sensors, security and wellbeing gadgets, home mechanization and in numerous modern instruments.

\section{B.7805 Voltage Regulator:}

The LM78XX course of action of 3-terminal controllers is available with settled yield voltages of $5 \mathrm{~V}, 8 \mathrm{~V}, 12 \mathrm{~V}$, and 15V.These devices require only a solitary outside fragment Compensation capacitor at the yield. The LM78XX game plan is bundled in the TO-220 power package and is prepared for giving 1.5A of yield current. These controllers use inside current confining safe domain protection and warm shutdown for security against in every way that really matters all over-weight conditions. Low ground stick current of the LM78XX course of action grants yield voltage to be easily helped over the present a motivating force with a resistor divider.

\section{LM317:}

The LM317 IC is an awesome, low power and simple to utilize double channel operation amp IC. It is composed and presented by national semiconductor. It comprises of two inside recurrence adjusted, high increase, and autonomous operation amps. This IC is intended for extraordinarily to work from a solitary power supply over an extensive variety of voltages., DC pick up pieces and transducer speakers. LM317 IC is a decent, standard operational enhancer and it is reasonable for your necessities. It can deal with 3-32V DC supply and source up to $20 \mathrm{~mA}$ for every channel.

\section{Liquid Crystal Display:}

A standout amongst the most widely recognized gadgets joined to a small scale controller is a LCD show. Probably the most widely recognized LCD's associated with the numerous microcontrollers are $16 \times 2$ and 20x2 showcases. This implies 16 characters for every line by 2 lines and 20 characters for each line by 2 lines, individually. 


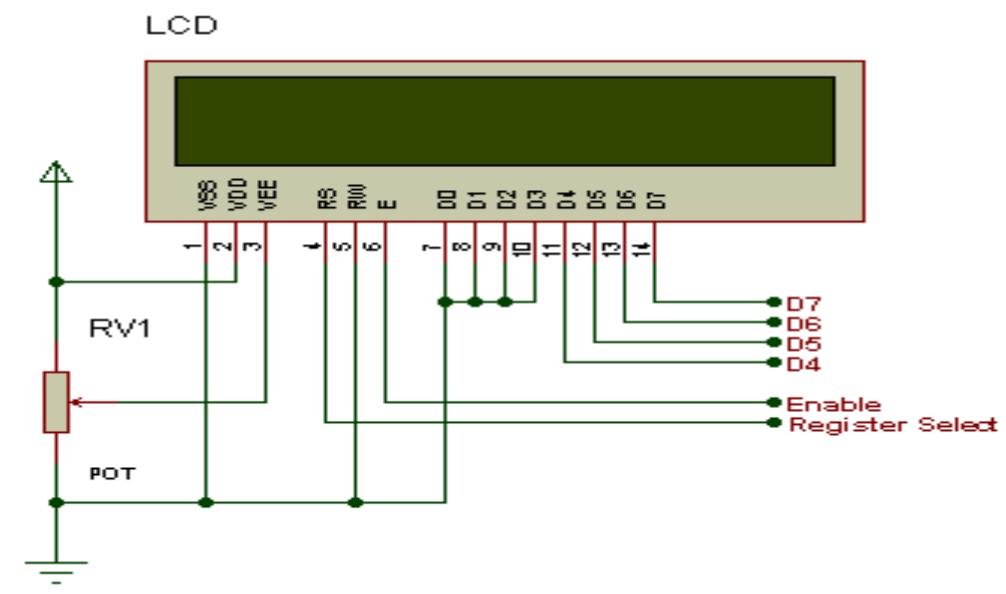

Fig.3LCD

\section{ADVANTAGES}

- Increased safety.

- Dedicated battery room space.

- Elimination of battery change-out.

- Operator time (reduced productivity).

- Minimize potential of accidents involving battery Changing.

- Purchase and maintenance of changing equipment.

\section{APPLICATIONS}

- Best suited for large capacity trucks.

- Power output is shared by the trucks that are Plugged in.

- It can be used for industrial application.

\section{RESULTS}

The battery charging voltage is displayed on the LCD as shown in fig below,

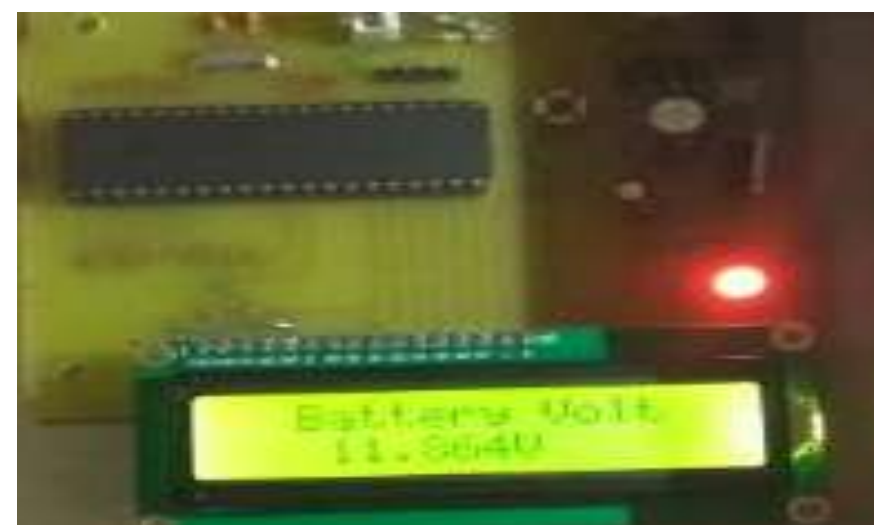

Fig4. voltage on LCD

\begin{tabular}{|l|l|l|}
\hline Sr. No. & Time & Voltage \\
\hline 1 & 0 & $3.71 \mathrm{~V}$ \\
\hline 2 & 2hrs. 55min. & $7.60 \mathrm{~V}$ \\
\hline 3 & 5hrs. 10min. & $10.37 \mathrm{~V}$ \\
\hline 4 & 6hrs. 05min. & $11.86 \mathrm{~V}$ \\
\hline
\end{tabular}

Tab. Observation table of readings of voltage after regular intervals. 


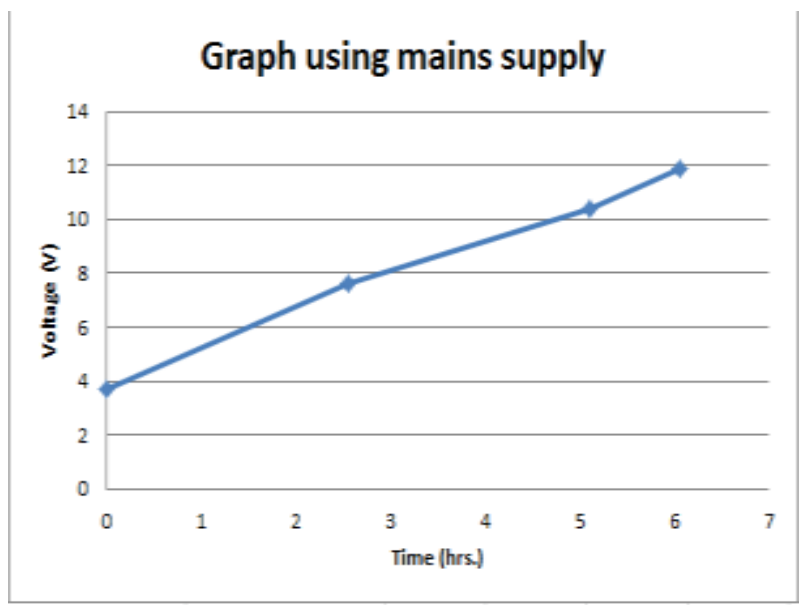

Fig 5.graph

\section{CONCLUSION}

It will charge the battery within less time. The high-power three-level dc-dc converter based fast charger with comprehensive dc power balance management isproposed for high-power charging stations with a bipolar dc bus. The proposed fast charger has the dc power balance capabilityand enables the elimination of additional balancing circuitsand high-frequency transformers, thereby improves the overall system efficiency.

\section{REFERENCES}

[1] M. Chris, M. M. Abul, and G. David, Power Electronics in HEVs: Plug-in Hybrid Electric Vehicles, in Hybrid Electric Vehicles: Principles and Applications with Practical Perspectives. Chichester, UK: Wiley, 2011.

[2] A. J. Collin, S. Z. Djokic, H. F. Thomas, and J. Meyer, "Modeling of electric vehicle chargers for power system analysis," in Proc. 2011 Int. Conf. Elect.Power Quality and Utilisation (EPQU), Oct. 2011, pp. 1-6.

[3] M. S. W. Chan, K. T. Chau, and C. C. Chan, "Modeling of electric vehicle chargers," in Proc. 24th Annu. IEEE Industrial Electronics Society Conf., Sep. 1998, vol. 1, pp. 433-438.

[4] R. Horton, J. Taylor, A. Maitra, and J. Halliwell, “A time-domain model of a plug-in electric vehicle battery charger," in Proc. 2012 IEEE PES Transmission and Distribution Conf. and Expo., May 2012, pp. 1-5.

[5] M. Hajian, H. Zareipour, and W. D. Rosehart, "Environmental benefits of plug-in hybrid electric vehicles: The case of Alberta," in Proc. IEEE Power Energy Soc. Gen. Meet., 2009, pp. 1-6.

[6] J. F. K. Morrow and D. Karner, "Plug-in hybrid electric vehicle charging infrastructure review," Battelle Energy Alliance, Idaho Falls, ID, USA, Tech. Rep. 58517, 2008.

[7] A. S. C. Botsford, "Fast charging versus slow charging pros and cons for the new age of electric vehicles," in Proc. 24th Elect. Vehicle Symp., 2009, pp. 1-9.

[8] L. Dickerman and J. Harrison, “A new car, a new grid,” IEEE Power Energy Mag., vol. 8, no. 2, pp. 55-61, Mar./Apr. 2010.

[9] B. Sanzhong and S. M. Lukic, "Unified active filter and energy storage system for an MW electric vehicle charging station," IEEE Trans. Power Electron., vol. 28, no. 12, pp. 5793-5803, Dec. 2013.

[10] S. Rivera, B. Wu, S. Kouro, V. Yaramasu, and J. Wang, "Electric vehicle charging station using a neutral point clamped converter with bipolar DC bus," IEEE Trans. Ind. Electron., 2014. DOI: 10.1109/TIE.2014.2348937

[11] B. Wu, High-Power Converters and AC Drives. New York, NY, USA: Wiley, 2006.

[12] B. Zhang and S. D. Pekarek, "Analysis and average value model of a source-commutated 5-phase rectifier," in Proc. IEEE PESC 2004, Aachen, Germany, 2004.

[13] P. Krause, O. Wasynczuk, and S. Sudhoff, Analysis of Electric Machinery and Drive Systems. New York: Wiley-IEEE Press, 2002.

[14] A. Dubey, S. Santoso, and M. P. Cloud, "Average-value model for plug-in hybrid electric vehicle battery chargers," in Proc. 2012 IEEE Power \& Energy Society General Meeting, Jul. 2012, pp. 1-8.

[15] I. A. Khan, "Battery chargers for electric and hybrid vehicles," Proc. 1994 Conf. Power Electronics in Transportation, pp. 103-112, Oct. 1994.

[16] W. Schalkwijk and B. Scrosat, Charging, Monitoring, and Control: Advances in Lithium-Ion Batteries. New York: Springer, 2002.

[17] Matlab and Simulink, TheMathworks, Inc, Sep. 2006 [Online]. Available: http://www.mathworks.com.

[18] Power System Simulation Software Manual. Winnipeg, MB, Canada: Monitoba HVDC Research Center, 1995. 